\title{
Isolation and optimized production of putative antimicrobial compounds from Egyptian soil isolate Streptomyces sp. MS. 10
}

Mohamed Sebak ${ }^{1 *}$ (D) Amal E. Saafan ${ }^{1,2} \mathbb{D}$, Sameh Abdelghani ${ }^{1}$, Walid Bakeer ${ }^{1} \mathbb{D}$, Abeer S. Moawad ${ }^{3}$ (D) and Ahmed O. El-Gendy ${ }^{1}$ (D)

\begin{abstract}
Background: The rapid spread of antibiotic resistance has increased research interest in the discovery of natural products, mainly from actinomycetes, which have been the primary source of antimicrobial compounds. This study aimed to isolate, characterize, and optimize the production of some of the bioactive compounds from bioactive soil actinomycetes.

Results: One promising soil actinomycete, which was molecularly identified as Streptomyces sp. and designated as Streptomyces sp. MS. 10, showed broad-spectrum antimicrobial activity, including activity against methicillin-resistant Staphylococcus aureus. Thus, it was selected for isolation of its major bioactive compounds. Polymerase chain reaction amplification of the genes responsible for antibiotic biosynthesis showed the presence of genes encoding type I and type II polyketide synthase. Liquid chromatography-mass spectrometry analysis found that the major antimicrobial compounds produced by Streptomyces sp. MS. 10 were weakly ionized bioactive secondary metabolites. A large-scale fermentation experiment of Streptomyces sp. MS. 10 using pre-optimized culture conditions followed by bioassay-guided chromatographic separation of its secondary metabolites resulted in the isolation of putative bioactive compounds that were identified as fatty acids using proton nuclear magnetic resonance spectroscopy.

Conclusions: Egyptian soil is still a good source for exploring bioactive actinomycetes. Additionally, this study highlighted the importance of combining both physicochemical and genotypic characterization with spectroscopic analysis of the major natural products when isolating bioactive metabolites.
\end{abstract}

Keywords: Actinomycetes, Antimicrobial natural products, Liquid chromatography-mass spectrometry, Methicillinresistant Staphylococcus aureus, Nuclear magnetic resonance, Streptomyces

\footnotetext{
*Correspondence: Mohamed.sebak@pharm.bsu.edu.eg

'Microbiology and Immunology Department, Faculty of Pharmacy, Beni-Suef University, Beni-Suef, Egypt

Full list of author information is available at the end of the article
}

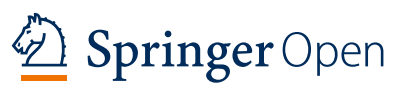

(c) The Author(s). 2021 Open Access This article is licensed under a Creative Commons Attribution 4.0 International License, which permits use, sharing, adaptation, distribution and reproduction in any medium or format, as long as you give appropriate credit to the original author(s) and the source, provide a link to the Creative Commons licence, and indicate if changes were made. The images or other third party material in this article are included in the article's Creative Commons licence, unless indicated otherwise in a credit line to the material. If material is not included in the article's Creative Commons licence and your intended use is not permitted by statutory regulation or exceeds the permitted use, you will need to obtain permission directly from the copyright holder. To view a copy of this licence, visit http://creativecommons.org/licenses/by/4.0/. 


\section{Background}

The substantial increase in the number of multidrugresistant microorganisms has led to a boost in the field of antibiotic discovery [1-4]. During 1981-2014, 45\% of all new antimicrobials approved by the Food and Drug Administration were either of natural origin (natural products or their derivatives) or synthetic drugs mimicking the mode of action or pharmacophores of natural products [5]. The natural products that are derived from microorganisms (bacteria and fungi) and their analogs and derivatives are the most successful defense line against infectious diseases $[5,6]$.

Species of the Streptomyces genus are responsible for producing $75 \%$ of the reported metabolites isolated from actinobacteria $[7,8]$. Some of these compounds play a critical role in ecological systems by suppressing microbial competitors in their environment to protect their food supply. The production of such bioactive metabolites demonstrates highly organized and coordinated metabolic pathways in Streptomyces sp., which allows them to dominate among other ecosystem inhabitants $[9,10]$. Streptomyces sp. have a high GC content, which is thought to accumulate over the years through selection processes of adaptation to new ecosystems and is believed to grant their dominance in soil niches [11]. Many secondary metabolites produced by Streptomyces sp. have been successfully used as antibiotics in the treatment of drug-resistant infections in both humans and animals [12].

This study aimed to use a bioassay-guided approach to isolate naturally occurring antimicrobial products from a crude extract of Streptomyces sp. MS. 10 using different chromatographic separation techniques, followed by their chemical characterization using spectroscopic techniques.

\section{Methods}

\subsection{Isolation and antimicrobial activity screening of} Streptomyces sp. MS. 10

Streptomyces sp. MS. 10 was recovered from a superficial soil layer sample collected from Ihnasia City in BeniSuef Governorate, Egypt. It was isolated on International Streptomyces Project (ISP) 4 agar using the soil dilution plate technique, as previously described [13, 14].

Antimicrobial activity screening of Streptomyces sp. MS. 10 was performed using the cup diffusion method [15] against the following indicator strains: Sarcina lutea (environmental sample), Bacillus subtilis (environmental sample), Enterococcus faecalis (food sample), Salmonella enterica (ATCC 35664), Pseudomonas aeruginosa (ATCC 9027), Proteus sp. (clinical sample), Escherichia coli (clinical sample), and methicillin-resistant Staphylococcus aureus (MRSA; clinical sample). Briefly, tryptone soya agar plates were surface inoculated with the indicator strains, followed by the use of a sterile borer to make $10-\mathrm{mm}$ cups in the agar plates that were filled with $150 \mu \mathrm{L}$ of the supernatant from a liquid broth culture of Streptomyces sp. MS. 10. The antimicrobial activity against each indicator strain was determined according to the diameter of the inhibition zones around the cups, following incubation for $24 \mathrm{~h}$ at the appropriate temperature for growth of each indicator strain. An inhibition zone diameter $\geq 12 \mathrm{~mm}$ was recorded as positive for bioactivity.

\subsection{Taxonomical identification using 16S rRNA gene sequencing}

Genomic DNA of Streptomyces sp. MS. 10 was extracted and purified, as previously described [16]. Then, polymerase chain reaction (PCR) amplification of the 16S rRNA gene was performed using forward primer 27F ( $5^{\prime}$-AGAGTTTG ATCMTGGCTCAG-3') and reverse primer 1492R (5'GGTTACCTTGTTACGACTT-3') [17]. The PCR reaction was performed in a final volume of $50 \mu \mathrm{L}$ using $10 \mu \mathrm{L}$ of $5 \times$ reaction buffer, $500 \mathrm{ng}$ of genomic DNA, a $10 \mathrm{mM}$ dNTP mixture, 2.5 units of Taq DNA polymerase, and $1 \mu \mathrm{L}$ of both forward and reverse primers. The PCR cycling conditions were as follows: initial denaturation of the DNA template for $3 \mathrm{~min}$ at $94{ }^{\circ} \mathrm{C}$; followed by 35 cycles of denaturation at $94{ }^{\circ} \mathrm{C}$ for $45 \mathrm{~s}$, annealing at $55^{\circ} \mathrm{C}$ for $60 \mathrm{~s}$, and extension at $72{ }^{\circ} \mathrm{C}$ for $60 \mathrm{~s}$; and a final extension at $72{ }^{\circ} \mathrm{C}$ for $5 \mathrm{~min}$.

Agarose gel electrophoresis $(1.5 \%, \mathrm{w} / \mathrm{v})$ was performed for $60 \mathrm{~min}$ at $90 \mathrm{~V}$ using $5 \mu \mathrm{L}$ of each PCR product to determine the success of PCR amplification and the purity of the PCR product. A 1-kb DNA ladder was also included to estimate the size of the PCR products [18]. The PCR product of the 16S rRNA gene was then purified using a PCR purification kit before being sequenced at Macrogen Korea using forward primer 785F (5'GGATTAGATACCCTGGTA-3') and reverse primer 907R (5' -CCGTCAATTCMTTTRAGTTT-3') [19].

The megaBLAST tool of the National Center for Biotechnology Information (NCBI) was used to compare the good-quality sequences of Streptomyces sp. MS. 10 with the GenBank database to identify the closest related strains that showed a high sequence similarity [20]. Then, we performed multiple sequence alignments of the amplified sequences and those obtained from GenBank, followed by phylogenetic analysis of Streptomyces sp. MS. 10 using the MEGA7 software [21].

\subsection{Fermentation and extraction of the bioactive compounds}

Bacterial fermentation of Streptomyces sp. MS. 10 was performed by inoculating tryptone soya broth (TSB) with a single pure colony and incubating for 3 days at $30^{\circ} \mathrm{C}$. Then, ISP4 broth was seeded with $5 \%$ bacterial inoculum in TSB and incubated on a rotary shaker at $160 \mathrm{rpm}$ for 7 days at $30{ }^{\circ} \mathrm{C}$. Next, the bacterial broth was filtered through a Whatman No. 1 filter, followed by the addition of ethyl acetate (EtOAc; $1: 1 \mathrm{v} / \mathrm{v}$ ), and the organic-aqueous mixture 
was shaken frequently in a separating funnel to aid the optimal extraction of the bioactive metabolites from the ISP4 broth. Finally, the organic layer was separated and collected in another flask, and the EtOAc solvent was evaporated using a rotary evaporator [16].

A small-scale fermentation experiment $(1.5 \mathrm{~L})$ was performed using the abovementioned culture conditions and extraction method. Then, a large-scale fermentation experiment $(10 \mathrm{~L})$ was performed using the preoptimized culture conditions, and the bioactive metabolites were extracted using the optimal extraction solvent $(1: 1 \mathrm{v} / \mathrm{v}$ dichloromethane $[\mathrm{DCM}])$, as discussed later.

\subsection{High-performance liquid chromatography}

The bioactive compounds in the EtOAc crude extract from the small-scale fermentation experiment were chromatographically separated by preparative HPLC on a Dionex Ultimate 3000 HPLC system (Agilent) using a Nucleosil C18 column. The solvent gradient started with $100 \% \mathrm{H}_{2} \mathrm{O}$ (HPLC grade) and $0 \%$ acetonitrile (ACN; HPLC grade) at a flow rate of $3 \mathrm{~mL} / \mathrm{min}$, and the percentage of $\mathrm{ACN}$ was linearly increased to $100 \%$ at $25 \mathrm{~min}$. Final washing was performed for $15 \mathrm{~min}$, using 100\% ACN Then, a second preparative HPLC run was performed on fraction 25 (retention time $\left[R_{\mathrm{t}}\right]=25 \mathrm{~min}$ ), which showed the highest antimicrobial activity, using the same protocol as the first HPLC run, except that the solvent gradient started with $30 \% \mathrm{H}_{2} \mathrm{O}$ and $70 \%$ methanol (HPLC grade) and linearly increased to $100 \%$ methanol at $25 \mathrm{~min}$, with final washing for 15 min using $100 \%$ methanol.

\subsection{Characterization of the major bioactive compounds}

We tested the effect of different temperatures and degrading enzymes, including protease, amylase, and $\alpha$ chymotrypsin, on the bioactivity of the supernatant from a liquid broth culture of Streptomyces sp. MS. 10 to characterize the major bioactive metabolites. Tubes containing $400 \mu \mathrm{L}$ of the broth supernatant were incubated for $30 \mathrm{~min}$ in water baths that were set to different temperatures $\left(60^{\circ} \mathrm{C}, 80^{\circ} \mathrm{C}\right.$, and $\left.100^{\circ} \mathrm{C}\right)$ to test the effect of temperature. The effect of $121^{\circ} \mathrm{C}$ on the major bioactive compounds was determined by autoclaving for $15 \mathrm{~min}$. To test the effect of degrading enzymes, they were separately added to the broth supernatant in different tubes. Their concentrations were adjusted to obtain a final concentration of $1 \mathrm{mg} / \mathrm{ml}$ in a final volume of $200 \mu \mathrm{L}$, and then the tubes were incubated at $37^{\circ} \mathrm{C}$ for $30 \mathrm{~min}$. Finally, the antimicrobial activity of all the treated broth supernatant samples was assessed using the agar diffusion method and compared with the activity of the original broth (positive control). Negative controls for the degrading enzymes were also included.

\subsection{PCR amplification of the genes responsible for antibiotic biosynthesis}

The genomic DNA of Streptomyces sp. MS. 10 was screened using PCR for the presence of genes responsible for the biosynthesis of natural products, including nonribosomal peptide synthetase (NRPS), polyketide synthase (PKS) I, PKS II, and glycopeptide monooxygenase B. The following primer pairs were used: NRPS/A3 F (5'-GCST ACSYSATSTACACSTCSGG-3') and NRPS/A7 R (5'SASGTCVCCSGTSGCGTAS-3') to amplify the NRPS gene, with an expected product size of 700 base pairs (bp) [22]; PKS/K1 F (5'-TSAAGTCSAACATCCGBCA-3') and PKS/M6 R (5'-CGCAGGTTSCSGTACCAGTA-3') to amplify the PKS I gene, with an expected product size of 1200-1400 bp [22]; ARO-PKS-F (5'-GGCAGCGGITTC GGCGGITTCCAG-3') and ARO-PKS-R (5'-CGITGTTI ACIGCGTAGAACCAGGCG-3') to amplify the PKS II gene, with an expected product size of 492-630 bp [23]; and oxyB F (5'-CTGGTCGGCAACCTGATGGAC-3') and oxyB R (5'-CAGGTACCGGATCAGCTCGTC-3') to amplify the glycopeptide monooxygenase $B$ gene, with an expected product size of $696 \mathrm{bp}$ [23]. The PCR cycling conditions included initial denaturation for $5 \mathrm{~min}$ at $94{ }^{\circ} \mathrm{C}$; followed by 40 successive cycles of denaturation for $30 \mathrm{~s}$ at $95^{\circ} \mathrm{C}$, annealing for $30 \mathrm{~s}$ at $59^{\circ} \mathrm{C}, 55^{\circ} \mathrm{C}, 64^{\circ} \mathrm{C}$, and $60^{\circ} \mathrm{C}$ for NRPS, PKS I, PKS II, and glycopeptide monooxygenase primers, respectively; and extension at $72^{\circ} \mathrm{C}$ for $2 \mathrm{~min}$. The final extension was at $72^{\circ} \mathrm{C}$ for $10 \mathrm{~min}$ [24]. The success of PCR amplification of the targeted genes was determined by running the PCR products on a $1.5 \%(\mathrm{w} / \mathrm{v})$ agarose gel using both 100-bp and 1-kb ladders as size markers [18].

\subsection{Optimization of the culture conditions and the extraction solvents}

We optimized the culture conditions for Streptomyces sp. MS. 10 to determine those necessary for the optimal production of the major antimicrobial compounds by comparing different growth media, carbon sources, and nitrogen sources [16]. The best culture media was selected by comparing the antimicrobial activity of Streptomyces sp. MS. 10 inoculated in different culture media, including ISP4, ISP4 supplemented with glucose, and TSB. The fermentation experiments for selecting best culture media were done using a shaker incubator at $160 \mathrm{rpm}$ for 7 days at $30^{\circ} \mathrm{C}$. The best carbon source was determined by replacing the starch in ISP4 broth with other carbon sources, including fructose, glucose, maltose, sucrose, lactose, glycerol, mannitol, and sorbitol, while the best nitrogen source was selected by replacing the ammonium sulfate in ISP4 broth with ammonium citrate, urea, peptone, tryptone, proteose peptone, albumin, casein, casamino acid, and yeast extract. The fermentation experiments for testing optimal carbon and nitrogen sources were done using a shaker incubator at $160 \mathrm{rpm}$ for 11 days at $30^{\circ} \mathrm{C}$ with daily sampling starting from day 3 . 
The extraction conditions were optimized using different organic solvents, including hexane, chloroform, DCM, and EtOAc, at different solvent: broth proportions. The cup diffusion method was used to screen for antimicrobial activity under the different extraction conditions. Extraction success was defined as the absence of activity in the fermentation broth after liquid/liquid extraction, indicating complete extraction of the total metabolites in the bacterial broth.

\subsection{Column chromatography}

A total of $250 \mathrm{mg}$ of crude extract was obtained from the extraction of the large-scale fermentation broth (10 L) of Streptomyces sp. MS. 10 using DCM $(1: 1, \mathrm{v} / \mathrm{v})$ for extraction. The bioactive secondary metabolites in the crude extract were chromatographically separated using a normal phase packed silica gel column (column chromatography) and gradient elution with DCM and methanol in 1\% increments until 100\% methanol. The packed silica column was prepared using $12.5 \mathrm{~g}$ of silica gel. Briefly, the dry crude extract of Streptomyces sp. MS. 10 was solubilized in DCM. Then, $0.5 \mathrm{~g}$ of silica was added, and the extract was left to dry to make a dry band, which was added to the top of the packed silica column. Fractions of $10 \mathrm{ml}$ each were collected, with a total of 160 fractions. The similarity of the collected fractions was checked using thin-layer chromatography (TLC) plates with DCM-methanol as the solvent system and p-anisaldehyde as the spray reagent, and the similar fractions were pooled. Additionally, the collected fractions were screened for antimicrobial activity using the cup diffusion method. Fractions showing good purity on the TLC plates and high antimicrobial activity were selected for further analysis using proton nuclear magnetic resonance $\left({ }^{1} \mathrm{H}\right.$ NMR) spectroscopy in an effort to determine their chemical classes.

\subsection{Spectroscopic characterization}

The most bioactive fraction from the second HPLC run (fraction 14) underwent analysis using liquid chromatography-mass spectrometry (LC-MS) at the Faculty of Postgraduate Studies of Advanced Science, BeniSuef University, Egypt, to determine the major ion peaks and their mass-to-charge ratios $(\mathrm{m} / z)$. LC-MS was performed in both the negative and positive ion modes using electrospray ionization. The bioactive compounds that were isolated from the large-scale fermentation experiment underwent ${ }^{1} \mathrm{H}$ NMR spectroscopy using a 400 MHz NMR system (Bruker) at the Faculty of Pharmacy, Beni-Suef University, Egypt [25]. The NMR solvent was deuterated methanol (MeOD).

\section{Results}

\subsection{Antimicrobial activity screening}

Preliminary identification of Streptomyces sp. MS. 10 as an actinomycete was made based on its mycelia coloration, pigment production, and morphological characteristics, followed by antimicrobial activity screening showing broad-spectrum activity against all tested indicator strains in this study, including MRSA. Therefore, Streptomyces sp. MS. 10 was selected for further isolation and purification of its bioactive metabolites using bioassay-guided chromatographic separation.

\subsection{Molecular identification using 16S rRNA gene sequencing}

A comparison of the partial $16 \mathrm{~S}$ rRNA gene sequence of Streptomyces sp. MS. 10 with sequences in GenBank showed high similarity (>99\%) with the sequences of many Streptomyces species. We performed multiple alignments of these sequences with the partial 16S rRNA gene sequence of Streptomyces sp. MS. 10 and constructed a phylogenetic tree using the maximum likelihood method in the MEGA7 software (Fig. 1) [21]. However, because of the high similarity of the 16S rRNA gene sequence of Streptomyces sp. MS. 10 with sequences of different species of Streptomyces, we could only confirm its genus as Streptomyces, and we were unable to determine its species. Thus, isolate MS. 10 was designated as Streptomyces sp., and its sequence was submitted to NCBI GenBank under accession number MN148619.

\subsection{Chromatographic separation of the bioactive metabolites from the small-scale fermentation experiment}

The first HPLC run performed on the crude extract of Streptomyces sp. MS. 10 resulted in the collection of 40 fractions, of which fraction 25 showed the best antimicrobial activity. However, it was insufficiently pure for further chemical identification, so it was subjected to a second fractionation run by preparative HPLC. Fraction $14\left(R_{\mathrm{t}}=14 \mathrm{~min}\right)$ eluted from the second HPLC run showed the highest zone of inhibition among all collected fractions. LC-MS analysis of the bioactive fraction 14 showed the presence of many major ion peaks (Fig. 2).

\subsection{Characterization of the major bioactive compounds}

Characterization of the major bioactive metabolites of Streptomyces sp. MS 10 revealed that they were unaffected by proteolytic enzymes (protease $\mathrm{K}$ and $\alpha$ - chymotrypsin) and amylase (Table 1). Thermal stability was observed at temperatures of up to $80^{\circ} \mathrm{C}$, and antimicrobial activity was diminished at $100^{\circ} \mathrm{C}$ and $121^{\circ} \mathrm{C}$ (autoclave) (Table 1). 


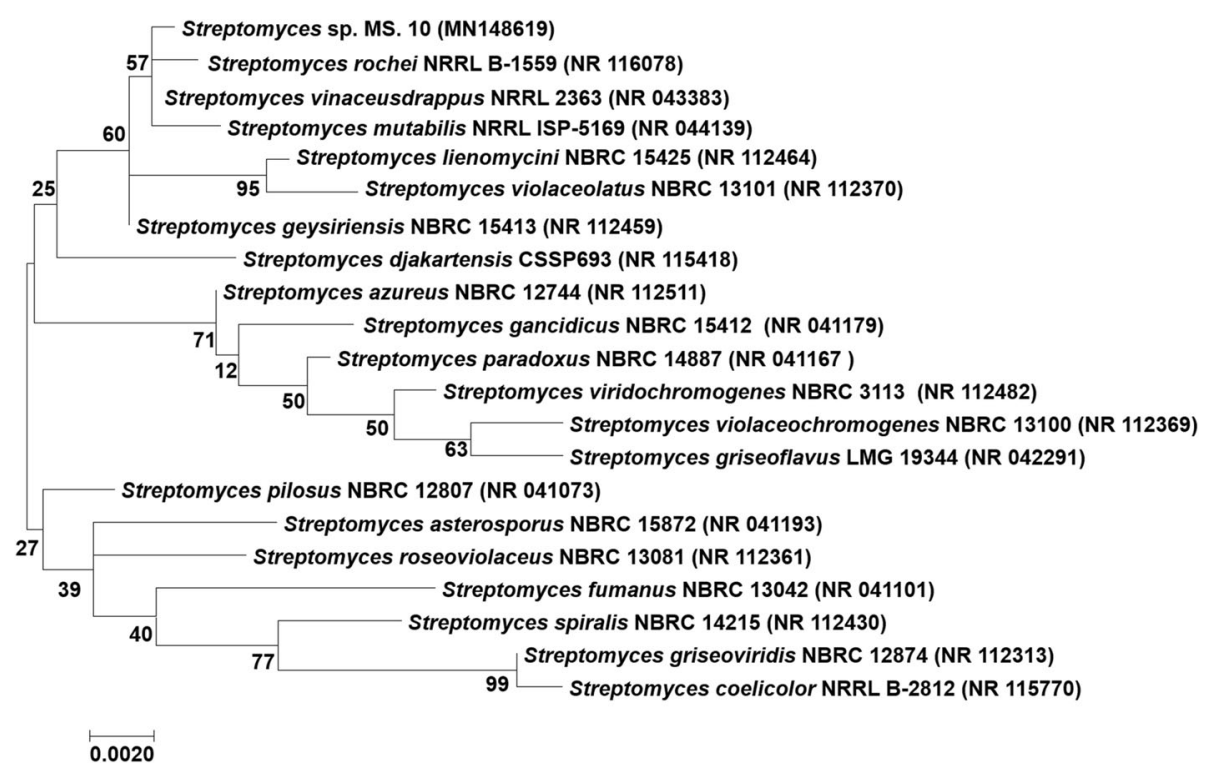

Fig. 1 Phylogenetic tree of Streptomyces sp. MS. 10 based on partial 16S rRNA gene sequences using the maximum likelihood method. The evolutionary history was inferred based on the Kimura 2-parameter model [26]. The tree with the highest log-likelihood $(-2875.0856)$ is shown. The percentage of trees in which the associated taxa clustered together is shown next to the branches. The initial tree(s) for the heuristic search were obtained automatically by applying the neighbor-joining and BioNJ algorithms to a matrix of pairwise distances estimated using the maximum composite likelihood approach and then selecting the topology with the most superior log-likelihood value. The tree is drawn to scale, with branch lengths measured in the number of substitutions per site. The analysis involved 21 nucleotide sequences. All positions containing gaps and missing data were eliminated. There were 1400 positions in the final dataset. The evolutionary analyses were conducted using the MEGA7 software [21]

\subsection{Molecular identification of the genes responsible for} antibiotic biosynthesis

PCR amplification of the screened genes revealed the absence of both NRPS and glycopeptide monooxygenase B genes in the genomic DNA of Streptomyces sp. MS. 10, whereas genes encoding PKS I and PKS II were detected using agarose gel electrophoresis to compare the size of the PCR products with size markers.

\subsection{Optimization of the culture conditions and the extraction solvent}

ISP4 broth was shown to be the best culture medium among those tested, leading to the optimal production

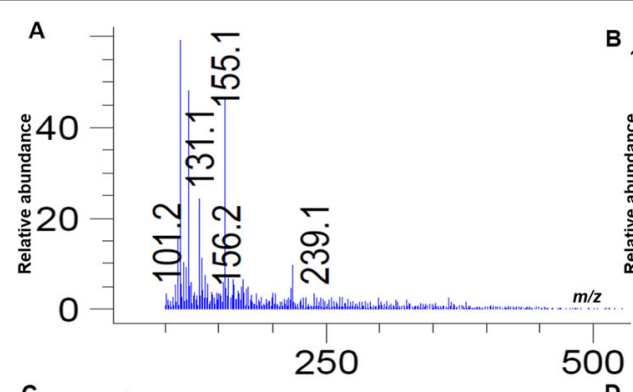

C
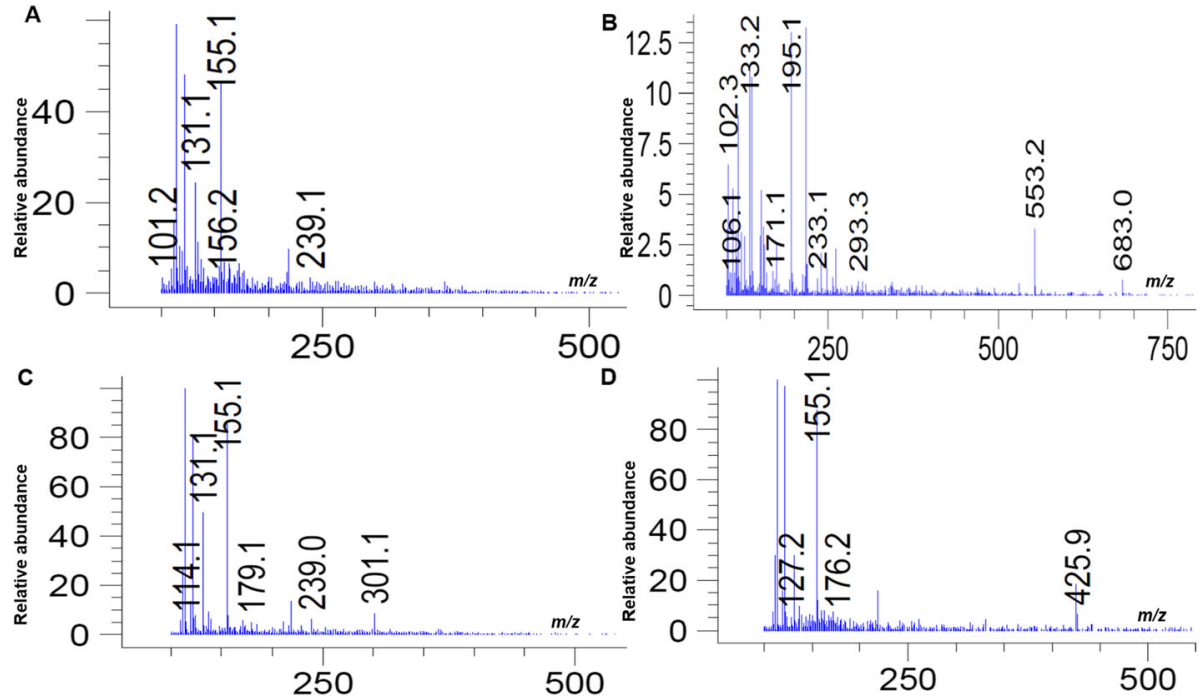

Fig. 2 Mass spectra of different ion peaks of fraction 14 at different $R_{\mathrm{t}}$ showing the detection of components with different $m / z$ values. a Mass spectrum at $R_{\mathrm{t}}=2.00 \mathrm{~min}$. b Mass spectrum at $R_{\mathrm{t}}=2.92 \mathrm{~min}$. c Mass spectrum at $R_{\mathrm{t}}=14.75$ min. $\mathbf{d}$ Mass spectrum at $R_{\mathrm{t}}=19.76$ min 
Table 1 Characterization of the total antimicrobial activity of Streptomyces sp. MS. 10

\begin{tabular}{ll}
\hline Test condition & Effect on antimicrobial activity \\
\hline Protease $\mathrm{K}$ & No effect \\
a-chymotrypsin & No effect \\
Amylase & No effect \\
$60^{\circ} \mathrm{C}$ & No effect \\
$80^{\circ} \mathrm{C}$ & No effect \\
$100^{\circ} \mathrm{C}$ & Diminished activity \\
Autoclave $\left(121^{\circ} \mathrm{C}\right)$ & Diminished activity \\
\hline
\end{tabular}

of the antimicrobial agents. This was followed by ISP4 supplemented with glucose, which showed a smaller inhibition zone diameter compared with using ISP4 alone. Replacing starch as the carbon source in ISP4 broth with different carbon sources, including monosaccharides, disaccharides, polysaccharides, and sugar derivatives, revealed maltose (disaccharide) as the optimal carbon source, showing the largest zone of inhibition. Casein was identified as the optimal nitrogen source among the tested nitrogen sources used to replace the ammonium sulfate in ISP4 broth, showing the largest inhibition zone.

Regarding extraction solvent optimization, DCM (1:1, $\mathrm{v} / \mathrm{v})$ was the best solvent to extract all antimicrobial agents from the fermentation broth, with no bioactivity remaining in the fermentation broth after the liquid/liquid extraction, and EtOAc in higher solvent: broth proportion $(2: 1, \mathrm{v} / \mathrm{v})$ showed the same result. Thus, $\operatorname{DCM}(1: 1, \mathrm{v} / \mathrm{v})$ was selected for further extraction of the total metabolites from the bacterial broth of Streptomyces sp. MS. 10 due to less solvent proportion required for total extraction of the bioactive compounds

\subsection{Chromatographic separation of the bioactive metabolites using column chromatography}

Among the 160 fractions collected following column chromatography, fractions 3-90 showed moderate to good antimicrobial activity in terms of inhibition zones, while fractions 7-9 and 21-35 showed the best activity, with the largest zone of inhibition. According to the antimicrobial activity and the TLC results, the highly bioactive fractions 8 and 24 were selected for spectroscopic analysis by ${ }^{1} \mathrm{H}$ NMR spectroscopy.

${ }^{1} \mathrm{H}$ NMR spectroscopy of fraction 8 suggested the presence of a saturated fatty acid (FA) as a major bioactive compound (Fig. 3). This was confirmed by the presence of both $\alpha$-protons, $\mathrm{H}_{2}-2$ resonating at $\delta_{\mathrm{H}} 2.38$ ppm and the long chain of methylene group $\left(\mathrm{CH}_{2}\right)_{\mathrm{n}}$ resonating at $\delta_{\mathrm{H}} 1.24-1.43 \mathrm{ppm}$, while the terminal methyl groups resonating at $\delta_{\mathrm{H}} 0.93$ were also detected (Fig. 3). Moreover, this FA was suggested as a saturated FA because of the absence of any olefinic protons which usually resonate at $\delta_{\mathrm{H}} 5.00-5.50 \mathrm{ppm}$. This final conclusion was also supported by elution of this compound by $90 \%$ DCM, which was the nonpolar solvent in the solvent gradient.

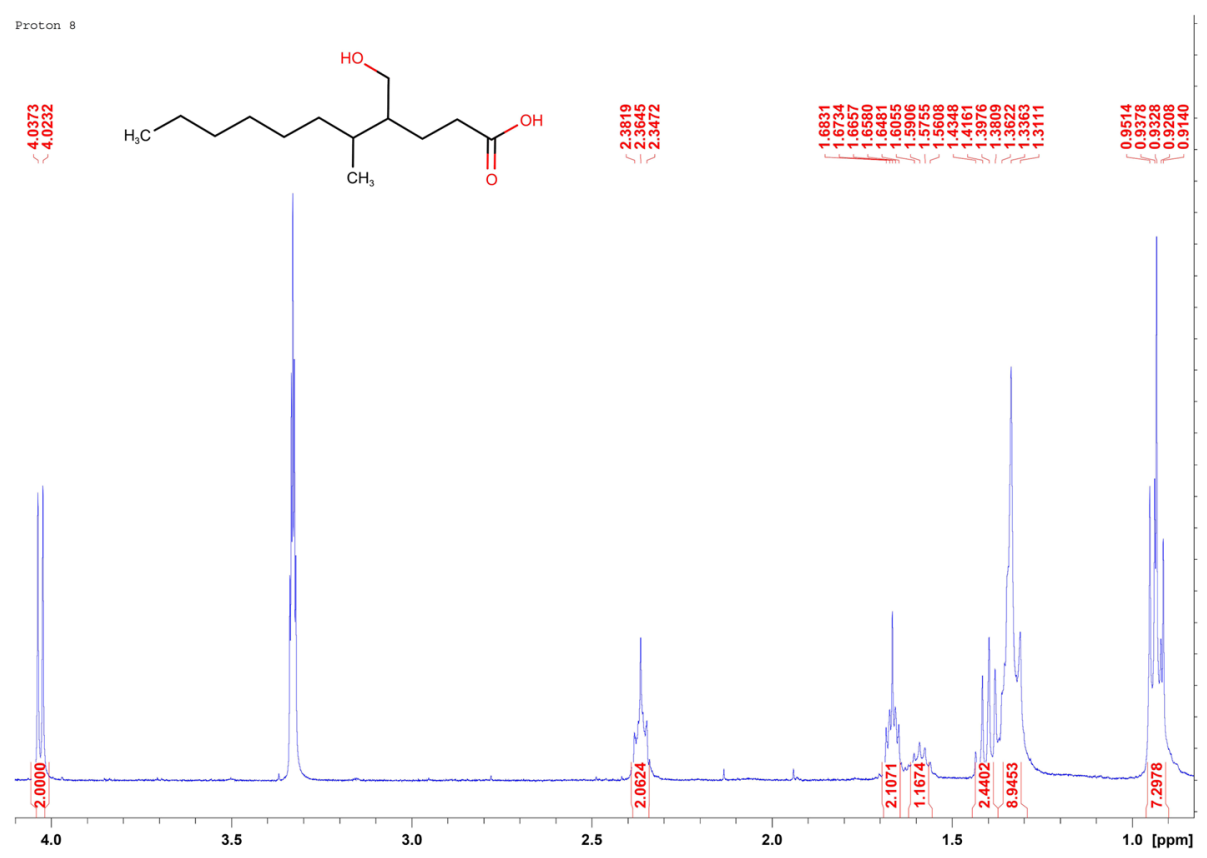

Fig. $3^{1} \mathrm{H}$ NMR spectroscopy of the major compound in fraction 8 in MeOD 
Proton-proton correlated spectroscopy $\left({ }^{1} \mathrm{H}-{ }^{1} \mathrm{H}\right.$ COSY $)$ and proton-carbon heteronuclear multiple bond correlation $\left({ }^{1} \mathrm{H}_{-}{ }^{13} \mathrm{C}\right.$ HMBC) NMR experiments confirmed the presence of saturated fatty acid as major bioactive compound in fraction 8 (Fig. S1 and Fig. S2). Both $\alpha-$ protons, $\mathrm{H}_{2}-2$ resonating at $\delta \mathrm{H} 2.38 \mathrm{ppm}$ and $\beta$ protons, $\mathrm{H}_{2}-3$ resonating at $\delta_{\mathrm{H}} 1.67 \mathrm{ppm}$ were coupled to each other as shown in the ${ }^{1} \mathrm{H}-{ }^{1} \mathrm{H}$ COSY spectrum (Fig. 4a and Fig. S1). Notably, the $\alpha$-protons, $\mathrm{H}_{2}-2$ and $\beta$-protons, $\mathrm{H}_{2}-3$ showed 2-bond correlation (2 $J$ ) and 3bond correlation $(3 /)$ to $C-1$ resonating at $\delta_{C} 173.91$ ppm (carboxylic group), respectively (Fig. $4 \mathrm{~b}$ and Fig. S2). Also, ${ }^{1} \mathrm{H}_{-}{ }^{1} \mathrm{H}$ COSY experiment revealed that $\beta$ protons, $\mathrm{H}_{2}-3$ and $\mathrm{H}-4$ resonating at $\delta_{\mathrm{H}} 1.59 \mathrm{ppm}$ were coupled to each other, and $\mathrm{H}-4$ was coupled to couple of protons resonating at $\delta_{\mathrm{H}} 4.03 \mathrm{ppm}$ and $\mathrm{H}-5$ resonating at $\delta_{\mathrm{H}} 1.4 \mathrm{ppm}$ (Fig. 4a and Fig. S1). Interestingly, the two protons $\left(\mathrm{H}_{2}\right)$ resonating at $\delta_{\mathrm{H}} 4.03 \mathrm{ppm}$ were deshielded suggesting that they were on a carbon atom linked to a heteroatom. By investigating the proton-carbon heteronuclear single quantum coherence $\left({ }^{1} \mathrm{H}^{13}{ }^{13} \mathrm{C}\right.$ HSQC) spectrum, it was clear that those deshielded protons were connected to a deshielded carbon resonating at $\delta_{C}$ $66.31 \mathrm{ppm}$ suggesting the presence of a heteroatom linked to this carbon (Fig. S3). This finding suggested the presence of a hydroxy FA as a major bioactive compound in fraction $8 .{ }^{1} \mathrm{H}_{-}{ }^{13} \mathrm{C}$ HMBC showed many interesting connectivity including connectivity between these deshielded protons and the $\mathrm{C}-1$ (carboxylic group) and C-4 resonating at $\delta_{\mathrm{C}} 38.82 \mathrm{ppm}$ (Fig. $4 \mathrm{~b}$ and Fig. S2).

Another branching of this FA was suggested by detecting three protons (methyl group) resonating at $\delta \mathrm{H} 0.93$ ppm coupled to $\mathrm{H}-5$ as shown in ${ }^{1} \mathrm{H}^{-}{ }^{1} \mathrm{H}$ COSY experiment (Fig. 4a and Fig. S1). ${ }^{1} \mathrm{H}_{-}{ }^{13} \mathrm{C}$ HMBC confirmed this suggestion by revealing the presence of 3-bond correlation ( $3 J$ ) between the methyl $\mathrm{H}_{3}$ and $\mathrm{C}-4$ and between $\mathrm{H}-5$ and the hydroxylated carbon atom (Fig. $4 \mathrm{~b}$ and Fig. S2). All carbons-protons assignments were done by ${ }^{1} \mathrm{H}_{-}{ }^{13} \mathrm{C}$ HSQC (Fig. S3). Finally, this compound was elucidated as a mono-hydroxylated saturated FA by comparison with literature [27, 28]. Determination of the length of the methylene group chain in this FA was challenging due to absence of its exact mass, so it was extracted from its ${ }^{1} \mathrm{H}$ NMR spectrum suggesting that the molecular formula of this FA was $\mathrm{C}_{13} \mathrm{H}_{26} \mathrm{O}_{3}$. However, this molecular formula cannot be confirmed without determining the exact mass. Therefore, this FA final structure was not confirmed, and it was shown as a proposed structure (Fig. 5).

The identification of the major bioactive compound in fraction 24 using ${ }^{1} \mathrm{H}$ NMR spectroscopy was more difficult than fraction 8 due to the presence of some impurities and one or more minor compound(s) (Fig. S4).

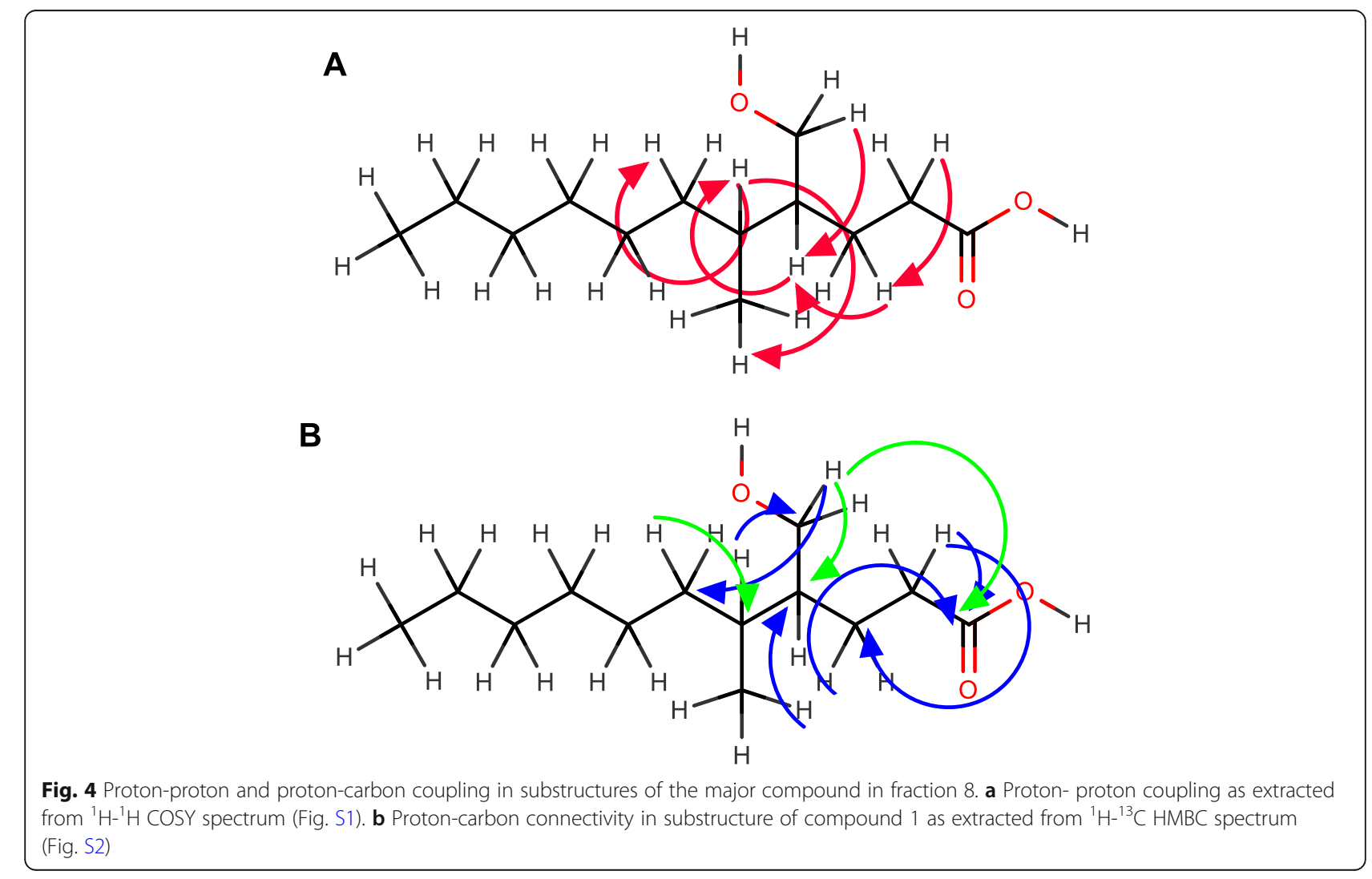




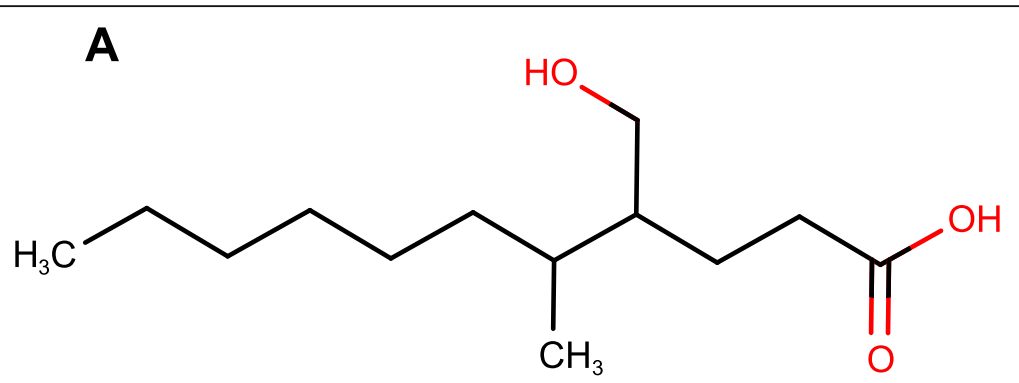

B<smiles>CCCCCCCC(=O)O</smiles>

Fig. 5 Proposed chemical structures of the major bioactive compounds from large-scale of Streptomyces sp. MS. 10. a Proposed chemical structure of the major bioactive compound in fraction 8. b Proposed chemical structure of the major bioactive compound in fraction 24

Similar to the major compound in fraction 8 , the presence of a saturated FA as a major compound in fraction 24 was proposed due to presence of both $\alpha$-protons of the FA, resonating at $\delta_{\mathrm{H}} 2.29 \mathrm{ppm}$, and the long chain of the methylene group, resonating at $\delta_{\mathrm{H}} 1.35-1.45 \mathrm{ppm}$, while the terminal methyl group(s), resonating at $\delta_{\mathrm{H}}$ 0.90, were also detected (Fig. 6). Also, similar to the FA in fraction 8 , the absence of proton chemical shifts in the olefinic region suggested the saturation of this FA.
${ }^{1} \mathrm{H}_{-}{ }^{1} \mathrm{H}$ COSY and ${ }^{1} \mathrm{H}_{-}{ }^{13} \mathrm{C}$ HMBC experiments confirmed the presence of saturated FA as major bioactive compound in fraction 8 (Fig. S5 and Fig. S6), while all carbons-protons assignments were done by ${ }^{1} \mathrm{H}_{-}{ }^{13} \mathrm{C}$ HSQC experiment (Fig. S7). Although this major compound was elucidated as saturated FA (Fig. 5), the length of its methylene group chain was not determined exactly due to absence of its exact mass and presence of other impurities (Fig. S4). Finally, the presence of this long-

Proton-24

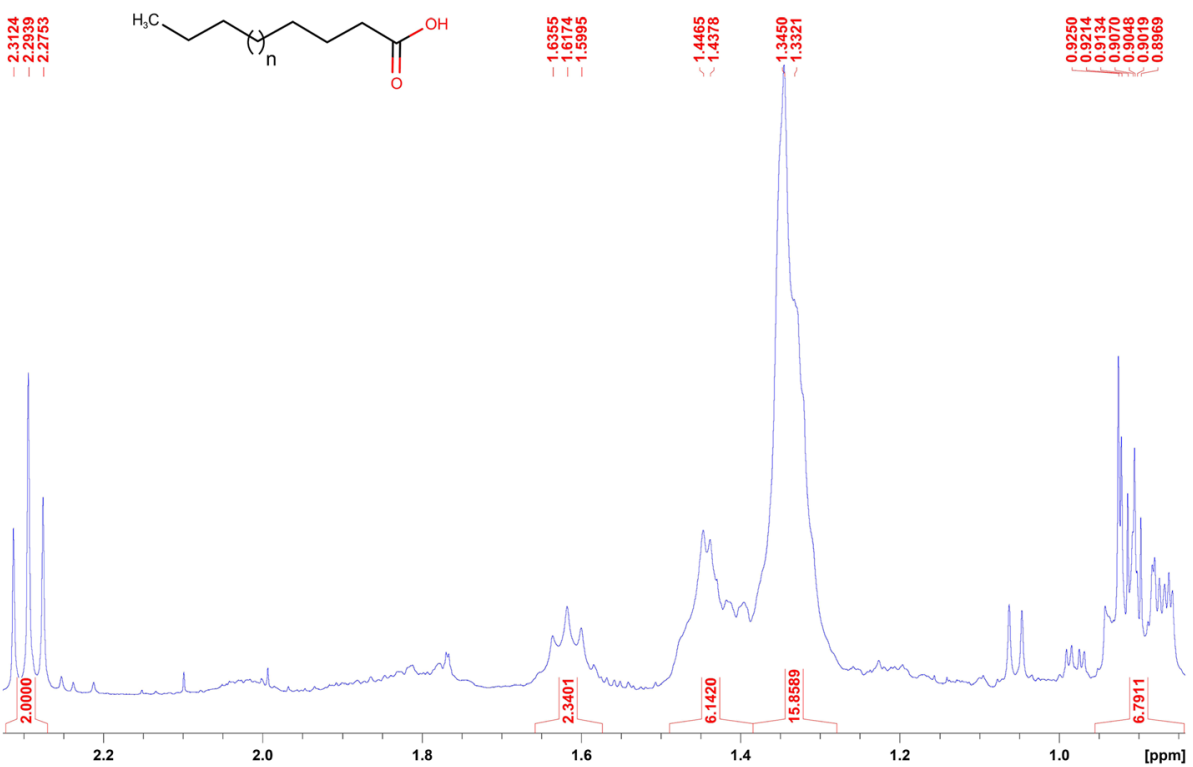

Fig. $6{ }^{1} \mathrm{H}$ NMR spectroscopy of the major compound in fraction 24 in MeOD 
chain saturated FA was confirmed by comparing with literature [29].

On the other hand, the presence of a sugar/peptide moiety, which might be part of a glycolipid/lipoprotein as a minor compound in fraction 24, was indicated from the small integration of some protons that resonating at $\delta_{\mathrm{H}} 3.00-5.00 \mathrm{ppm}$ (Fig. S4). Similarly, an aromatic compound was also detected as a minor compound in fraction 24 because the integration of the protons resonating at $\delta_{\mathrm{H}} 6.28-7.75 \mathrm{ppm}$ was minimal compared with those of the major saturated FA. The two minor compounds were suggested to be either an FA derivative (glycolipid/lipoprotein) with another minor aromatic compound or only one minor compound containing both the sugar/peptide moiety and the aromatic moiety, which might be a glycolipid/lipoprotein linked to an aromatic moiety.

\section{Discussion}

We isolated an actinomycete (Streptomyces sp. MS. 10) with broad-spectrum antimicrobial activity and chemically isolated bioactive compounds from its crude extract, thereby achieving our study aim. The isolation of a broad-spectrum actinomycete from a soil sample confirmed the richness of the soil niche with bioactive actinomycetes [16].

Streptomyces sp. MS. 10 was molecularly identified as Streptomyces sp. due to the high similarity of its $16 \mathrm{~S}$ rRNA gene sequence with different species of Streptomyces, confirming the findings of an old report that $16 \mathrm{~S}$ rRNA sequencing was insufficient to assign the phylogeny of the closely related species [30]. On the other hand, another study conducted in 2004 reported that $16 \mathrm{~S}$ rRNA gene sequencing could be useful for phylogenetic identification of some strains at the species level but not others [31].

After HPLC fractionation of the crude extract from the small-scale fermentation experiment of Streptomyces sp. MS. 10, LC-MS analysis of the bioactive fraction 14 showed many major ion peaks, although it was expected that only one or very few major ion peaks would be detected in its mass spectrum. This suggested low ionization of the major compound(s) in this fraction, which was restated by highly ionized minor compounds also appearing as major peaks (Fig. 2). A similar strategy to isolate and identify natural microbial products using HPLC and LC-MS was followed earlier [16]; however, they used NMR spectroscopy to completely identify the isolated bioactive compounds, which was not applicable in our study due to the low dry weight of the isolated compounds. Therefore, we optimized the culture conditions for the production of the bioactive metabolites and subsequently upscaled the Streptomyces sp. MS. 10 fermentation experiment to produce higher amounts of the targeted antimicrobial compounds prior to their chromatographic separation using column chromatography.

The optimization results showed that ISP4 broth was the best culture medium among the tested media for the optimal production of antimicrobial agents by Streptomyces sp. MS. 10. Similarly, ISP4 broth supplemented with $0.4 \%$ yeast extract has been used for the production of many bioactive compounds by Streptomyces sp. [32]. Notably, another study compared the use of ISP4 broth for antibiotic production against ISP2 broth, starch-nitrate broth, and tryptone-yeast extract-glucose broth, revealing that ISP4 broth was the best fermentation broth among the tested culture media [33]. Replacing starch as carbon source and ammonium sulfate as the nitrogen source in ISP4 broth with different carbon and nitrogen sources, respectively, showed the importance of these feeding experiments because the bioactivity of Streptomyces sp. MS. 10 in terms of the size of the zone of inhibition was greatly affected, as mentioned earlier. A study has reported that the maximum expression of some antibiotics was achieved using glucose (monosaccharide) and lactose (disaccharide) as carbon sources [34], while another study showed that ammonium nitrate and soya meal were the best nitrogen sources in terms of antimicrobial activity [35], but this did not include the testing of casein. Optimization of the best solvent for extracting the major bioactive metabolites in the current study revealed that DCM $(1: 1, \mathrm{v} / \mathrm{v})$ was the best to extract the major antimicrobial agents. Another study that used different solvents $(1: 1, \mathrm{v} / \mathrm{v})$, including EtOAc, methanol, and chloroform, to extract the bioactive compounds and compared the zones of inhibition of the solvent extracts revealed that EtOAc was the best among the tested solvents [36], which partially matches our findings that EtOAc was the second-best solvent after DCM, which was not tested in this previous study.

Characterization of the major bioactive compounds was previously described in old reports using different methods of characterization $[35,37,38]$. The use of different methods could help to more comprehensively identify the nature of the major bioactive compounds for subsequent chemical isolation. The stability of the major bioactive metabolites of Streptomyces sp. MS. 10 against different enzymes and at temperatures of up to $80^{\circ} \mathrm{C}$ demonstrated that its major bioactive compounds were neither peptides nor starchy compounds. This was supported by the detection of genes encoding PKS I and PKS II, suggesting the presence of polyketide secondary metabolites 
among the natural products yielded by Streptomyces sp. MS. 10 [39], while the absence of the NRPS gene suggested that peptides were not the main bioactive compounds. Interestingly, both PKS I and PKS II have been detected in Streptomyces sp. [39, 40], while in another study, only PKS II was detected in the genomic DNA of Streptomyces sp. AGM12-1 [16].

After scaling-up Streptomyces sp. MS. 10 fermentation to $10 \mathrm{~L}$ using the pre-optimized culture and extraction conditions, we followed an earlier strategy of separation and characterization of the bioactive compounds using column chromatography followed by spectroscopic analysis [35]. Interestingly, the collected fractions that showed the highest antimicrobial activity were predicted to be fatty compounds or compounds with lipid moieties because they were eluted with solvent proportions of more than 90:10 (DCM: methanol). This was confirmed by structural elucidation of the isolated bioactive compounds using ${ }^{1} \mathrm{H}$ NMR spectroscopy, which showed the presence of two FAs as the major bioactive compounds with a minor FA derivative. Indeed, the absence of an effect of protease enzymes on the total antimicrobial activity of Streptomyces sp. MS. 10 and the failure to detect the NRPS gene using PCR amplification supported the idea that peptides were not the major bioactive compounds in its crude extract. Thus, it was supposed that the detected minor FA derivative was a glycolipid rather than a lipoprotein. It was also suggested that this supposed glycolipid had a small sugar moiety because amylase did not affect the total antimicrobial activity of Streptomyces sp. MS. 10 and because of the small integration of the protons of this moiety in the ${ }^{1} \mathrm{H}$ NMR spectrum.

The presence of FAs and their derivatives as major bioactive compounds in the crude extract of Streptomyces sp. MS. 10 may explain the reason behind the difficulty in determining the ion peaks of the major bioactive compounds from the small-scale fermentation experiment using LC-MS because many of the FAs do not ionize well using electrospray ionization prior to their mass detection. Therefore, other minor compounds, which could possibly be highly ionized, appeared as major compounds besides the true major compounds. Different FAs and their derivatives, including monohydroxy FAs [41], polyhydroxy FAs [42], and keto acids [43], have been isolated from Streptomyces.

Furthermore, FAs have been reported to have antibacterial activity, including activity against Staphylococcus epidermidis and E. coli [44], as well as activity against $S$. aureus [45]. Interestingly, two hydroxylated FAs similar to the major compound in fraction 8 showed antibacterial activity against Bacillus subtilis, Micrococcus luteus, and Staphylococcus aureus although these FAs were isolated from plant origin [27]. Additionally, highlighting the importance of the FAs produced by actinobacteria, this group of compounds were mostly identified as constituents of more complex compounds in actinomycetes, such as the lipopeptide antibiotic complex A21978 C, which is produced by Streptomyces roseosporus [46], and amphomycin, another lipopeptide antibiotic [47]. Furthermore, approximately $50 \%$ of the simple microbial glycolipids are produced by actinobacteria [48], and some glycolipids show antimicrobial activity [49].

\section{Conclusions}

The present study suggested the importance of the bioassay-guided approach in the chromatographic separation of major bioactive metabolites in crude microbial extracts. Furthermore, we proved that the soil niche is still a good source of actinomycetes that produce bioactive secondary metabolites. Moreover, PCR screening of the genes responsible for antibiotic biosynthesis and the physicochemical characterization of the total antimicrobial activity could help to predict, target, and subsequently, isolate the major bioactive compounds from crude microbial extracts.

\section{Supplementary Information}

The online version contains supplementary material available at https://doi. org/10.1186/s43088-021-00099-7.

Additional file 1: Figure S1. ${ }^{1} \mathrm{H}-{ }^{1} \mathrm{H}$ COSY spectrum for the major compound in fraction 8, measured in MeOD. Figure S2. ${ }^{1} \mathrm{H}^{-13} \mathrm{C} \mathrm{HMBC}$ spectrum for the major compound in fraction 8, measured in MeOD.

Figure S3. ${ }^{1} \mathrm{H}-{ }^{13} \mathrm{C}$ HSQC spectrum for the major compound in fraction 8, measured in MeOD. Figure S4. Full ${ }^{1} \mathrm{H}$ NMR spectrum of fraction 24, measured in MeOD. Figure S5. ${ }^{1} \mathrm{H}-{ }^{1} \mathrm{H}$ COSY spectrum for the major compounds in fraction 24, measured in MeOD. Figure S6. ${ }^{1} \mathrm{H}-{ }^{13} \mathrm{C} \mathrm{HMBC}$ spectrum for the major compound in fraction 24, measured in MeOD. Figure S7. ${ }^{1} \mathrm{H}-{ }^{13} \mathrm{C}$ HSQC spectrum for the major compounds in fraction 24, measured in MeOD.

\section{Abbreviations}

${ }^{1} \mathrm{H}$ NMR: Proton nuclear magnetic resonance; ACN: Acetonitrile; Bp: Base pair; COSY: Correlated spectroscopy; DCM: Dichloromethane; EtOAc: Ethyl acetate; FA: Fatty acid; HMBC: Heteronuclear multiple bond correlation; HPLC: Highperformance liquid chromatography; HSQC: Heteronuclear single quantum coherence; ISP: International Streptomyces Project; LC-MS: Liquid chromatography-mass spectrometry; MRSA: Methicillin-resistant Staphylococcus aureus; MeOD: Deuterated methanol; m/z: Mass-to-charge ratio; NCBI: National Center for Biotechnology Information; NRPS: Nonribosomal peptide synthetase; PCR: Polymerase chain reaction;

PKS: Polyketide synthase; $R_{\mathrm{t}}$ : Retention time; TLC: Thin-layer chromatography; TSB: Tryptone soya broth

\section{Acknowledgements}

We are so grateful to Dr. Ahmed Farag Azmy for supplying us with some clinical isolates for antimicrobial activity screening and to Dr. Tarek Dishisha for his kind help and recommendations in the optimization steps.

\section{Authors' contributions}

All microbiology experiments were designed by AOE and revised by AES, WB, and SA. All chromatographic separation experiments and spectroscopic analysis in the study were designed by ASM. Isolates collection and purification, 16S rRNA sequences analysis, and LC-MS sample submission 
were carried out by MS and AOE, while the biological activity, the chromatographic separation work, and the NMR data processing were performed by MS. All project's results were interpenetrated by MS and AOE. This research project was supervised by AES, SA, ASM, WB, and AOE. The initial draft of this manuscript was written by $M S$ and revised by $S A, A S M, W B, A O E$, and $A E S$ prior to its submission. The author(s) read and approved the final manuscript.

\section{Funding}

This research received no external funding.

\section{Availability of data and materials}

The $16 \mathrm{~S}$ rRNA gene sequence of Streptomyces sp. MS. 10 was submitted to NCBI Genbank under accession number MN148619.

\section{Ethics approval and consent to participate}

This article does not contain any experiment done on either humans or animals.

\section{Consent for publication}

Not applicable.

\section{Competing interests}

The authors declare no conflict of interest.

\section{Author details}

${ }^{1}$ Microbiology and Immunology Department, Faculty of Pharmacy, Beni-Suef University, Beni-Suef, Egypt. ${ }^{2}$ Department of Pharmaceutical Microbiology, Faculty of Pharmacy, Menoufia University, Shebin El-Koum, Egypt. ${ }^{3}$ Department of Pharmacognosy, Faculty of Pharmacy, Beni-Suef University, Beni-Suef, Egypt.

Received: 10 September 2020 Accepted: 8 January 2021 Published online: 23 January 2021

\section{References}

1. Alvin A, Miller Kl, Neilan BA (2014) Exploring the potential of endophytes from medicinal plants as sources of antimycobacterial compounds. Microbiol Res 169:483-495. https://doi.org/10.1016/j.micres.2013.12.009

2. Strobel G, Daisy B (2003) Bioprospecting for microbial endophytes and their natural products. Microbiol Mol Biol Rev 67:491-502. https://doi.org/10. 1128/mmbr.67.4.491-502.2003

3. Wu C, Kim HK, Van Wezel GP, Choi YH (2015) Metabolomics in the natural products field - a gateway to novel antibiotics. Drug Discov Today Technol 13:11-17. https://doi.org/10.1016/j.ddtec.2015.01.004

4. Yu H, Zhang L, Li L, Zheng C, Guo L, Li W, Sun P, Qin L (2010) Recent developments and future prospects of antimicrobial metabolites produced by endophytes. Microbiol Res 165:437-449. https://doi.org/10.1016/j.micres. 2009.11.009

5. Newman DJ, Cragg GM (2016) Natural products as sources of new drugs from 1981 to 2014. J Nat Prod 79:629-661. https://doi.org/10.1021/acs. jnatprod.5b01055

6. Cragg GM, Newman DJ (2013) Natural products: a continuing source of novel drug leads. Biochim Biophys Acta, Gen Subj 1830:3670-3695. https:// doi.org/10.1016/j.bbagen.2013.02.008

7. Undabarrena A, Beltrametti F, Claverías FP, González M, Moore ERB, Seeger M, Cámara B (2016) Exploring the diversity and antimicrobial potential of marine actinobacteria from the comau fjord in Northern Patagonia, Chile. Front Microbiol 7:1135. https://doi.org/10.3389/fmicb.2016.01135

8. Lam KS (2007) New aspects of natural products in drug discovery. Trends Microbiol 15:279-289. https://doi.org/10.1016/j.tim.2007.04.001

9. Hic-Tomic T, Genčić MS, Živković MZ, Vasiljevic B, Djokic L, Nikodinovic-Runic J, Radulović NS (2015) Structural diversity and possible functional roles of free fatty acids of the novel soil isolate Streptomyces sp. NP10. Appl Microbiol Biotechnol 99:4815-4833. https://doi.org/10.1007/s00253-0146364-5

10. Chevrette MG, Carlson CM, Ortega HE, Thomas C, Ananiev GE, Barns KJ, Book AJ, Cagnazzo J, Carlos C, Flanigan W, Grubbs KJ, Horn HA, Hoffmann FM, Klassen JL, Knack JJ, Lewin GR, McDonald BR, Muller L, Melo WGP, Pinto-Tomás AA, Schmitz A, Wendt-Pienkowski E, Wildman S, Zhao M, Zhang F, Bugni TS, Andes DR, Pupo MT, Currie CR (2019) The antimicrobial potential of Streptomyces from insect microbiomes. Nat Commun 10:516. https://doi.org/10.1038/s41467-019-08438-0

11. Kemung HM, Tan LTH, Khan TM, Chan KG, Pusparajah P, Goh BH, Lee LH (2018) Streptomyces as a prominent resource of future anti-MRSA drugs. Front Microbiol 9:1-26. https://doi.org/10.3389/fmicb.2018.02221

12. Cho SS, Choi YH, Simkhada JR, Mander P, Park DJ, Yoo JC (2012) A newly isolated Streptomyces sp. CS392 producing three antimicrobial compounds. Bioprocess Biosyst Eng 35:247-254. https://doi.org/10.1007/s00449-0110599-7

13. Sebak M, Saafan AE, AbdelGhani S, Bakeer W, El-Gendy AO, Espriu LC, Duncan K, Edrada-Ebel R (2019) Bioassay- and metabolomics-guided screening of bioactive soil actinomycetes from the ancient city of Ihnasia, Egypt. PLoS One 14:e0226959. https://doi.org/10.1371/journal.pone.0226959

14. Williams ST, Goodfellow M, Wellington EMH, Vickers JC, Alderson G, Sneath PH, Sackin MJ, Mortimer AM (1983) A probability matrix for identification of some streptomycetes. J Gen Microbiol 129:1815-1830. https://doi.org/10. 1099/00221287-129-6-1815

15. Gavin JJ (1957) Analytical microbiology. II. The diffusion methods. Appl Microbiol 5:25-33. https://doi.org/10.1128/aem.5.1.25-33.1957

16. Ahmad MS, El-Gendy AO, Ahmed RR, Hassan HM, El-Kabbany HM, Merdash AG (2017) Exploring the antimicrobial and antitumor potentials of Streptomyces sp. AGM12-1 isolated from Egyptian soil. Front Microbiol 8:438. https://doi.org/10.3389/fmicb.2017.00438

17. Silva MB (2016) Percepção da população assistida sobre a inserção de estudantes de medicina na Unidade Básica de Saúde. Trab conclusão curso 1:1-10. https://doi.org/10.1017/CBO9781107415324.004

18. Sambrook J, Fritsch EF, Maniatis T (1989) Molecular cloning: a laboratory manual. Cold spring harbor laboratory press, New York

19. Unissa R, Sudhakar M, Reddy ASK (2015) Screening of marine bacterial cultures for extracellular production of I-arginine deiminases. World J Pharm Res 4:1194-1204

20. Benson DA, Clark K, Karsch-Mizrachi I, Lipman DJ, Ostell J, Sayers EW (2014) GenBank. Nucleic Acids Res 42:D32-D37. https://doi.org/10.1093/nar/ gkt1030

21. Kumar S, Stecher G, Tamura K (2016) MEGA7: Molecular evolutionary genetics analysis version 7.0 for bigger datasets. Mol Biol Evol 33:1870-1874. https://doi.org/10.1093/molbev/msw054

22. Passari AK, Mishra VK, Saikia R, Gupta VK, Singh BP (2015) Isolation, abundance and phylogenetic affiliation of endophytic actinomycetes associated with medicinal plants and screening for their in vitro antimicrobial biosynthetic potential. Front Microbiol 6:273. https://doi.org/ 10.3389/fmicb.2015.00273

23. Wood SA, Kirby BM, Goodwin CM, Le Roes M, Meyers PR (2007) PCR screening reveals unexpected antibiotic biosynthetic potential in Amycolatopsis sp. strain UM16. J Appl Microbiol 102:245-253. https://doi. org/10.1111/j.1365-2672.2006.03043.x

24. Baker GC, Smith JJ, Cowan DA (2003) Review and re-analysis of domainspecific 165 primers. J Microbiol Methods 55:541-555. https://doi.org/10. 1016/j.mimet.2003.08.009

25. El-Hawary SS, Mohammed R, AbouZid S, Ali ZY, El-Gendy AO, Elwekeel A (2016) In-vitro cyclooxygenase inhibitory, antioxidant and antimicrobial activities of phytochemicals isolated from crassula arborescens (Mill.) Willd. Int J Appl Res Nat Prod 9:8-14

26. Kimura M (1980) A simple method for estimating evolutionary rates of base substitutions through comparative studies of nucleotide sequences. J Mol Evol 16:111-120. https://doi.org/10.1007/BF01731581

27. Sarwar R, Faroog U, Naz S, Riaz N, Majid Bukhari S, Rauf A, Mabkhot YN, AlShowiman SS (2018) Isolation and characterization of two new antimicrobial acids from Quercus incana (Bluejack Oak). Biomed Res Int 2018

28. Koshino H, Togiya S, Yoshihara T, Sakamura S, Shimanuki T, Sato T, Tajimi A (1987) Four fungitoxic C-18 hydroxy unsaturated fatty acids from stromata of Epichloe typhina. Tetrahedron Lett 28:73-76. https://doi.org/10.1016/ S0040-4039(00)95652-1

29. Misra TN, Singh RS, Upadhyay J, Srivastava R (1984) Isolation of a natural sterol and an aliphatic acid from Vernonia cinerea. Phytochemistry 23:415-417

30. Doolittle WF (1988) Bacterial evolution. Can J Microbiol 34:547-551. https:// doi.org/10.1139/m88-093

31. Song J, Lee SC, Kang JW, Baek HJ, Suh JW (2004) Phylogenetic analysis of Streptomyces spp. isolated from potato scab lesions in Korea on the basis of 165 rRNA gene and 16S-23S rDNA internally transcribed spacer sequences. Int J Syst Evol Microbiol 54:203-209. https://doi.org/10.1099/ijs.0.02624-0 
32. Masand M, Sivakala KK, Menghani E, Thinesh T, Anandham R, Sharma G, Sivakumar N, Jebakumar SRD, Jose PA (2018) Biosynthetic potential of bioactive streptomycetes isolated from arid region of the Thar desert, Rajasthan (India). Front Microbiol 9:687. https://doi.org/10.3389/fmicb.2018. 00687

33. Rabah FL, Elshafei A, Saker M, Cheikh B, Hocine H (2007) Screening, isolation and characterization of a novel antimicrobial producing actinomycete, strain RAF10. Biotechnology 6:489-496. https://doi.org/10.3923/biotech.2007.489. 496

34. Ilić SB, Konstantinović SS, Savić DŠS, Veljković VB, Gojgić-Cvijović G (2010) The impact of Schiff bases on antibiotic production by Streptomyces hygroscopicus. Med Chem Res 19:690-697. https://doi.org/10.1007/s00044009-9223-7

35. Kandula SK, Terli R (2013) Production, purification and characterization of an antimicrobial compound from marine Streptomyces coeruleorubidus BTSS301. J Pharm Res 7:397-403. https://doi.org/10.1016/j.jopr.2013.04.047

36. Parthasarathi S, Sathya S, Bupesh G, Manikandan M, Kim CJ, Manikandan T, Balakrishnan K (2013) Isolation, characterization and extraction of antimicrobial compound from marine actinomycete Streptomyces hygroscopicus BDUS 49. Res J Biotechnol 8:40-48

37. Jain PK, Jain PC (2007) Isolation, characterization and antifungal activity of Streptomyces sampsonii GS 1322. Indian J Exp Biol 45:203-206

38. Kabuki T, Nakajima H, Arai M, Ueda S, Kuwabara Y, Dosako S (2000) Characterization of novel antimicrobial compounds from mango (Mangifera indica L.) kernel seeds. Food Chem 71:61-66. https://doi.org/10.1016/S03088146(00)00126-6

39. Hakvåg S, Fjærvik E, Josefsen KD, lan E, Ellingsen TE, Zotchev SB (2008) Characterization of Streptomyces spp. isolated from the sea surface microlayer in the Trondheim Fjord, Norway. Mar Drugs 6:620-635. https:// doi.org/10.3390/md6040620

40. Ohnishi Y, Ishikawa J, Hara H, Suzuki H, Ikenoya M, Ikeda H, Yamashita A, Hattori M, Horinouchi S (2008) Genome sequence of the streptomycinproducing microorganism Streptomyces griseus IFO 13350. J Bacteriol 190: 4050-4060. https://doi.org/10.1128/JB.00204-08

41. Kurata I, Umekita M, Sawa T, Hattori S, Hayashi C, Kinoshita N, Homma Y, Igarashi M, Hamada M, Watanabe T, Sawa R, Naganawa H, Takahashi Y, Akamatsu Y (2010) Paleic acid, a fatty acid from Paenibacillus sp.: taxonomy, fermentation, isolation, structure determination, and anti-Mannheimia andPasteurella activity. J Antibiot (Tokyo) 63:519-523. https://doi.org/10.1038/ja. 2010.90

42. Viegelmann C, Margassery LM, Kennedy J, Zhang T, O'Brien C, O'Gara F, Morrissey JP, Dobson ADW, Edrada-Ebel RA (2014) Metabolomic profiling and genomic study of a marine sponge-associated Streptomyces sp. Mar Drugs 12:3323-3351. https://doi.org/10.3390/md12063323

43. Ma M, Rateb ME, Yang D, Rudolf JD, Zhu X, Huang Y, Zhao LX, Jiang $Y$, Duan Y, Shen B (2017) Germicidins H-J from Streptomyces sp. CB00361. J Antibiot (Tokyo) 70:200-203. https://doi.org/10.1038/ja.2016.100

44. Isaacs CE, Kashyap S, Heird WC, Thormar H (1990) Antiviral and antibacterial lipids in human milk and infant formula feeds. Arch Dis Child 65:861-864. https://doi.org/10.1136/adc.65.8.861

45. Aly R, Maibach HI, Shinefield HR, Strauss WG (1972) Survival of pathogenic microorganisms on human skin. J Invest Dermatol 58:205-210. https://doi. org/10.1111/1523-1747.ep12539912

46. Zmijewski MJ, Briggs B, Occolowitz J (1986) Role of branched chain fatty acid precursors in regulating factor profile in the biosynthesis of A21978 C complex. J Antibiot (Tokyo) 39:1483-1485. https://doi.org/10.7164/ antibiotics.39.1483

47. Heinemann B, Kaplan MA, Muir RD, Hooper IR (1953) Amphomycin, a new antibiotic. Antibiot Chemother (Northfield, III) 3:1239-1242

48. Abdel-Mawgoud AM, Stephanopoulos G (2018) Simple glycolipids of microbes: chemistry, biological activity and metabolic engineering. Synth Syst Biotechnol 3:3-19. https://doi.org/10.1016/j.synbio.2017.12.001

49. de Jesus Cortes-Sanchez A, Hernández-Sánchez H, Jaramillo-Flores ME (2013) Biological activity of glycolipids produced by microorganisms: new trends and possible therapeutic alternatives. Microbiol Res 168:22-32. https://doi.org/10.1016/j.micres.2012.07.002

\section{Publisher's Note}

Springer Nature remains neutral with regard to jurisdictional claims in published maps and institutional affiliations.

\section{Submit your manuscript to a SpringerOpen ${ }^{\circ}$ journal and benefit from:}

- Convenient online submission

- Rigorous peer review

- Open access: articles freely available online

- High visibility within the field

- Retaining the copyright to your article

Submit your next manuscript at $\boldsymbol{\nabla}$ springeropen.com 